\title{
ESCRITA E IDENTIDADES
}

\author{
Izabel Magalhães
}

\section{Abstract}

The focus of this paper is on gender identities at work place adult literacy. Based on the concept of discourse as a crucial dimension of social practices in relation to other dimensions, mainly power, the paper addresses the issue of identity change in past narratives and their recontextualisation associated with work place current demands. The research findings suggest that women and men use different strategies in relation to literacy.

Key words: Gender identities, critical discourse theory, literacy practices, power, discourse rights, linguistic difference.

\section{INTRODUÇão}

As atuais transformações no contexto do trabalho, ligadas ao novo capitalismo, exigem um constante esforço representado nas práticas identitárias e nas experiências lingüísticas vivenciadas nas contradições entre o passado e o presente. O foco do estudo é sobre a forma como as diferenças lingüísticas produzem desigualdades no contexto do ensino e da aprendizagem da leitura e da escrita em português como língua materna no local de trabalho (Magalhães, $2004)^{1}$. A análise abordará o seguinte: as escolhas lingüísticas, a distri-

\footnotetext{
${ }^{1}$ Parte deste estudo foi apresentada no colóquio "Negotiating Communication Rights in Sites of Linguistic Difference", organizado por Simon Gieve (Universidade de Leicester), no Sociolinguitics Symposium 15, na Universidade de Newcastle, Newcastle upon Tyne, Grã-Bretanha, em abril de 2004. O texto do artigo foi apresentado no VIII Congresso Luso-Afro-Brasileiro de Ciências Sociais, na Universidade de Coimbra, Portugal, em setembro de 2004, em painel organizado por Luiz Paulo da Moita Lopes (UFRJ).
} 
buição do conhecimento lingüístico, as condições em que a diferença nos direitos discursivos é considerada problemática e as estratégias para lidar com a diferença lingüística. O trabalho é uma contribuição para o estudo dos direitos discursivos, baseados na discussão das possibilidades de resolução dos problemas comunicativos, alguma coisa além da crítica, que se localiza nas fronteiras das atuais "tensões e contradições" (Fairclough, 2000a: 183).

Voltando-se para as transformações identitárias, o estudo aponta diferenças nas representações discursivas das identidades femininas e masculinas (Cameron, 1995; Talbot, 1998; Walsh, 2001 - veja resenha neste número). Walsh apresenta três modelos de estudo das identidades de gênero: o modelo de acomodação, o modelo da diferença e o modelo performativo. $\mathrm{O}$ modelo da acomodação defende que as mulheres devem adotar as normas masculinas na esfera pública ${ }^{2}$, com base na percepção de que tais normas estão associadas ao poder. $\mathrm{O}$ modelo da diferença defende que as mulheres devem questionar as normas masculinas, promovendo "um estilo de discurso mais cooperativo" (op. cit., p. 5). O modelo performativo, associado à obra de Butler (1990), considera a identidade de gênero em termos da alternância entre as normas masculinas e as femininas.

Este trabalho adota a perspectiva da teoria crítica do discurso (TCD), situando o estudo do discurso na teoria social crítica. Como sugerem Chouliaraki e Fairclough (1999: 4), um aspecto significativo do estudo das transformações da modernidade posterior é a ênfase nas mudanças na linguagem e no discurso. Conforme assinalam:

Essas teorias criam um espaço para a análise de discurso crítica (ADC) como elemento fundamental na teorização e na análise crítica da modernidade posterior, mas como elas não são especificamente orientadas para a

\footnotetext{
${ }^{2} \mathrm{O}$ estudo da esfera pública é associado a Habermas. Por exemplo, a discussão sobre a "ética do discurso" na ação comunicativa (Habermas, trad., 1989). Fairclough (2000a) retoma a discussão da esfera pública, relacionando-a ao conceito de ordem do discurso político da 'governança': "o governo das organizações sociais e das instituições, não apenas o Governo" (op. cit., p. 172).
} 
linguagem não preenchem esse espaço adequadamente. É aqui onde a ADC tem uma contribuição a fazer. (Chouliaraki e Fairclough, 1999: 4) ${ }^{3}$

Nessa perspectiva, estudamos as diferenças lingüísticas no campo do letramento, que é considerado um espaço social com posições delimitadas, interrelacionado com recursos simbólicos. A distribuição dos recursos simbólicos é interconectada com as relações de poder derivadas de um contexto histórico profundamente afetado por desigualdades sociais, de gênero, classe social, etnia e raça (Magalhães, 1995ª 1995b, 1995c, 1996; Moita Lopes, 2002).

As transformações identitárias de que falamos fazem parte dos processos sociais relacionados às transformações econômicas e culturais contemporâneas (Giddens, 1991; Harvey, trad., 2000). Algumas dessas transformações econômicas e culturais se materializam textualmente em leis que determinam a perda de direitos trabalhistas consagrados, como por exemplo, a Reforma da Previdência e a flexibilização das leis que regem o trabalho formal (Fairclough, 2003; Magalhães, 2004b). "Os textos como elementos dos eventos sociais (...) causam efeitos - isto é, eles causam mudanças" (Fairclough, 2003: 8). Porém, os efeitos sociais dos textos precisam ser compreendidos, pois não se trata de 'simples causalidade mecânica'. Por exemplo, não cabe dizer que determinados aspectos dos textos transformam a vida das pessoas. Além disso, causalidade não é o mesmo que regularidade. Não existe uma relação de causa e efeito que seja regularmente associada com um tipo de texto ou com aspectos dos textos. Todavia, os textos produzem efeitos sobre as pessoas, e tais efeitos são determinados pela relação dialética entre texto e contexto social (Fairclough, 2001a).

O trabalho está dividido em quatro seções, além da introdução e da conclusão. Na próxima seção, serão apresentados os conceitos teóricos e, nas seções seguintes, a análise.

3 No artigo "Teoria crítica do discurso e texto", fazemos uma distinção entre teoria e análise de discurso críticas (cf. Magalhães, I., 2004a). Com relação às diversas formas de análise textual recomendadas aos(às) analistas críticos(as), sugerimos a leitura da excelente contribuição de Fairclough (2003). 


\section{O Letramento COMO Discurso}

Os conceitos teóricos principais do trabalho são: campo, poder e discurso (Bourdieu, 1991; Bernstein, 1996; Chouliaraki e Fairclough, 1999; Fairclough, 2003). Para Bourdieu, as pessoas de diversas classes sociais são diferentes porque 'inculcaram' diferentes disposições. Um conjunto particular de disposições é um 'habitus', que determina práticas, atitudes, percepções e valores sociais. As práticas, atitudes, percepções e valores sociais são produtos da relação entre o habitus e o contexto social do indivíduo. Bourdieu adota mais de um termo para discutir o contexto social; um desses termos é 'campo'. Um campo é um espaço social em que as posições sociais estão interrelacionadas com a distribuição de recursos, inclusive os recursos simbólicos/lingüísticos, que Bourdieu denomina 'capital'. Um ponto que cabe destacar no trabalho de Bourdieu é que uma forma de capital (por exemplo, lingüístico/educacional) pode ser transformada em outra (por exemplo, um emprego lucrativo).

Um conceito semelhante de campo foi desenvolvido por Bernstein. Bernstein também trata de aspectos como, por um lado, o acesso a posições, a tomada e a distribuição de posições, as práticas e estratégias com relação à acumulação de capital, e, por outro, a distribuição de habitus, o qual é selecionado e legitimado pelo campo. Entretanto, Bernstein discorda de Bourdieu ao falar sobre o sistema simbólico. Segundo Bourdieu (1991: 170), o poder simbólico não está na linguagem ou na semiótica, mas na relação entre os sujeitos que exercem poder e os que se submetem ao poder. Ao contrário, Bernstein (1996: 170) entende que a linguagem e o campo interagem como partes de um único sistema.

Concordando com Bernstein, diremos que o estudo da linguagem e da semiose é fundamental para a compreensão das práticas de leitura e escrita, denominadas 'práticas de letramentó' (Street, 1984). Nossa abordagem do letramento como discurso tem muito em comum com Fairclough (1989, 2000b, 2001b, 2003) e com os Novos Estudos do Letramento, propostos por Street $(1984,1995,2000)$ e desenvolvidos por Gee (1990), Barton (1994), Baynham (1995), Barton e Hamilton (1998), Barton et al. (orgs., 2000) e Martin-Jones e Jones (orgs., 2000). 
Investigadores de diversas orientações teóricas apontam a necessidade de estudo do discurso para a compreensão das práticas sociais contemporâneas. Chouliaraki e Fairclough (1999: 23) se referem às "práticas de produção". Para esses autores, uma prática de produção "envolve pessoas particulares em relações particulares usando recursos particulares - aplicando 'tecnologias' a 'materiais' em relações sociais particulares de produção." As tecnologias e os materiais devem ser considerados num sentido amplo, dos recursos físicos (materiais brutos) aos recursos simbólicos, como imagens, fotografias, desenhos, discursos e gêneros discursivos. Fairclough (2003) aprofunda a compreensão das práticas sociais com o detalhamento da análise textual, pois o discurso é uma dimensão das práticas.

Neste trabalho, investigamos práticas discursivas de letramento, que são sentidos históricos que direcionam a produção e a interpretação de textos falados, escritos e semióticos (Magalhães, 1995ª). As práticas discursivas de letramento constituem identidades, valores e crenças nos eventos de letramento, em que os textos e a forma como as pessoas falam sobre os textos contribuem para modelar os encontros e as relações sociais (Heath, 1983). Um ponto importante sobre as práticas é que elas articulam elementos discursivos com outros não-discursivos, por exemplo o poder (Fairclough, 2003: 25).

O letramento como discurso é defendido também por Gee (1990: 150), que escreve: "Acredito que é somente no contexto da noção de Discurso que podemos alcançar uma definição viável de letramento." Segundo Barton e Hamilton (2000: 9), as práticas de letramento estão situadas em relações assimétricas de poder e algumas dessas práticas são dominantes, enquanto outras são invisíveis. Essas idéias são derivadas da visão de letramento de Street $(1984,1995)$.

Os conceitos debatidos nesta seção fundamentam a análise que se segue.

\section{TransformaÇões identitárias E ASSIMETRIAS DE PODER}

Os dados que serão analisados pertencem ao nosso projeto de pesquisa Discurso e Identidade nos Contextos da Sala de Aula, do Trabalho e da 
Comunidade $^{4}$. A metodologia de coleta de dados é etnográfica ${ }^{5}$. A análise será baseada em 8 entrevistas ( 4 mulheres e 4 homens), realizadas na primeira etapa da pesquisa, e um segundo conjunto de entrevistas, com 6 das pessoas entrevistadas anteriormente ( 3 mulheres e 3 homens). A realização da segunda entrevista é recomendada na pesquisa etnográfica (Barton e Hamilton, 1998). Serão focalizadas principalmente as entrevistas com A, 48 anos, copeira; B, 52 anos, porteiro; e C, 30 anos, copeira. Ao responderem às seguintes perguntas: a) "Qual foi o motivo para você freqüentar este curso?"; b) "O que mudou depois que você começou a freqüentar o curso?”; e c) "O que significa a alfabetização para as mulheres e para os homens?", os alfabetizandos apresentam narrativas sobre as condições passadas e presentes, focalizando a questão da diferença lingüística. No contexto do trabalho, a alfabetização é situada nas relações assimétricas de poder. Além disso, é considerada como forma de aperfeiçoamento do trabalho ("melhorá assim no trabalho") e de promoção. Os dados foram coletados em duas instituições, o Ministério da Educação e o Ministério da Agricultura, em Brasília. As mulheres e os homens que participam do programa de alfabetização trabalham como copeiras, atendentes, vigias e porteiros.

Como foi observado na Introdução, a análise dos dados levará em conta: 1) as escolhas lingüísticas (Português Padrão/Não-Padrão); 2) a distribuição do conhecimento lingüístico; 3) as condições em que a diferença nos direitos discursivos é considerada problemática; e 4) as estratégias para lidar com a diferença lingüística.

\subsection{As ESCOLHAS LINGÜÍSTICAS}

Os dados indicam que o letramento é legitimado como um campo de poder, associado com a variedade padrão do português. Os entrevistados, aprendizes do Programa de Alfabetização de Adultos no local de trabalho, associam o aperfeiçoamento na produção escrita em Português Padrão com a aquisição de conhecimento lingüístico específico do trabalho ligado à comunicação com o/a chefe, à comunicação ao telefone, à comunicação

\footnotetext{
${ }^{4} \mathrm{O}$ projeto é financiado pelo $\mathrm{CNPq}$.

${ }^{5}$ Sobre a combinação da análise de discurso com a pesquisa etnográfica, ver Magalhães (2000).
} 
diária e ao preenchimento de fichas. B, porteiro no Ministério da Educação, faz o seguinte comentário: "muitas vezes, a pessoa falava alguma coisa e eu ficava caçando o que significava aquilo, hoje...já tem muitas coisas que... eu já sei o quê que é." A crença no poder/conhecimento do Português Padrão escrito é uma das formas em que as diferenças lingüísticas constroem identidades desiguais para os diferentes falantes.

Respondendo à pergunta "O que mudou depois que você começou a freqüentar o curso?”, B se refere à 'relação com os colegas', pois para relacionar-se com as pessoas, é necessário conhecer as 'palavras corretas'. O sentimento do aprendiz, de incapacidade para comunicar-se com as pessoas e de estar em desvantagem em sua relação com os outros, é atribuído ao fato de que ele não fala a variedade prestigiada do português. Ao mesmo tempo, considera incorreta sua maneira de falar.

\subsection{A distribuição do CONHecimento Lingüístico}

No contexto da alfabetização de adultos no local de trabalho, o letramento faz parte do trabalho dos entrevistados nos ministérios, assim o processo de sua legitimação é burocrático. Há, portanto, uma distribuição desigual do conhecimento lingüístico, com a exigência de realização de tarefas, como a leitura e a produção escrita de breves textos, e o preenchimento de fichas.

3.3 As CONDIÇÕES EM QUE A DIFERENÇA NOS DIREITOS DISCURSIVOS É CONSIDERADA PROBLEMÁTICA

A ausência do conhecimento da leitura e da escrita é associada ao Português Não-Padrão. Por exemplo, A comenta sobre o que mudou no seu trabalho após o início do curso de alfabetização. No comentário, destacam-se o item lexical 'vergonha' e a oração 'a gente fala muito errado', que foi repetida duas vezes na segunda entrevista, deixando clara a divisão que ela percebe entre o grupo que pertence à cultura letrada e o grupo no qual está situada, que precisa aprender a 'conversar com as pessoas', como forma de aperfeiçoar o desempenho no trabalho. B, também, destaca sua 'dificuldade' semântica/pragmática de compreensão do sentido do que lhe diziam. 


\subsection{As ESTRATÉGIAS PARA LIDAR COM A DIFERENÇA LINGÜÍSTICA}

Uma estratégia é a aprendizagem da escrita, tanto em relação à diferença lingüística como em relação às demandas do trabalho. Os entrevistados consideram que o letramento ampliou seus recursos comunicativos, com a aprendizagem do Português Padrão. Isso significa que a realização de cursos no local de trabalho é uma estratégia para obter promoção no futuro. A nota que seu desempenho mudou e que melhorou sua auto-estima, tornando-se auto-confiante para comunicar-se com os outros. B enfatiza os significados do letramento no desempenho do seu trabalho, na comunicação ao telefone, na produção escrita de mensagens e no desempenho de rituais da cultura letrada. Exemplos desses rituais são: bater na porta do/a chefe antes de entrar, pedir licença para falar e, ainda, falar de uma forma que as pessoas possam compreendê-lo. $\mathrm{C}$ comenta em detalhe as formas de tratamento que dirige às pessoas 'de alto nível' no momento de servir o café: senhor, senhora, doutor, sua excelência (Exemplo 1).

\section{EXEMPLO 1}

Pergunta: O que mudou no seu trabalho depois que você começou a freqüentar o curso de alfabetização?

C: Ah mudô muita coisa, mudô, a gente pra falá com as pessoas né? Que a gente às vezes falava com a pessoa tinha medo de falá errado, e a pessoa ficá rindo depois, eles não ri na hora né, porque uma vez já aconteceu isso comigo, não sei foi uma palavra que eu falei com uma pessoa, e ela falô, ficô olhando assim pra mim, eu falei ai meu Deus eu errei, aí eu tentei voltar atrás, corrigi, fez foi piorar, aí ficô rindo da gente, aí falei assim, ah, sacanagem, que eu por exemplo parei de estudá muito cedo né? Aí, mas hoje é diferente, a gente sabe falá com as pessoas direito né, sabe começá, falá com eles direitinho, não erro mais as palavras, como dirigi um, a pessoa sim, de alto nível né, a gente não sabia, senhora, doutô né, excelência, antigamente eu falava você, não tinha...é tu não tinha como distinguir né? Como é o doutô, doutô é um pouco mais alto da classe né? Igual ao doutô Marcelo né? Ministro, tem que chegá e falá sua excelência, antes eu falava um bocado de coisa errada, eu não sabia, agora não, a gente já sabe, distinguir né, do nível baixo pro nível alto, é muito bom, pelo menos não erra como eu 
que sou copeira, de servir café essas coisas assim, tem sabê falá senhor, senhor aceita, se não aceita, senhor quer isso, quer aquilo, então a gente tem que ter educação né? Igual uma vez eu fui servi um café, não bati na porta, pô devia ter batido na porta primeiro, pra poder entrá e pedir licença, agora não, eu entro bato na porta, peço licença, e aí pergunto se quer café, se não quer, é bom, muito bom.

\section{As IDENTIDADES DE GÊNERO}

Considerando agora todas as entrevistas realizadas, foi identificada uma diferença nas estratégias adotadas por mulheres e homens ao lidarem com a diferença lingüística. Para as mulheres, desenvolver o conhecimento do Português Padrão no curso de alfabetização significa o aperfeiçoamento de sua qualificação profissional, com vistas à obtenção de igualdade de direitos com os homens. Dada a tradicional divisão de gênero na sociedade brasileira, esse é um dado significativo que representa uma transformação identitária. Entretanto, a transformação identitária feminina coexiste com a preocupação em aprender a ler e escrever para auxiliar os filhos nas tarefas escolares (Magalhães, 2003). A coexistência dessas identidades conflitantes é parte das transformações socioculturais das últimas décadas. Tal conflito não está presente entre os homens entrevistados, cuja estratégia é voltada unicamente para a aquisição de novos conhecimentos e habilidades para promoção no trabalho.

Além da diferença nas estratégias adotadas por mulheres e homens, o presente estudo sugere a recontextualização das narrativas do passado, pois tanto os homens como as mulheres reconhecem que as demandas de então no campo do letramento diferiam radicalmente do presente (Bernstein, 1999). Veja o Exemplo 2.

\section{Exemplo 2}

Pergunta: O que significa a alfabetização para você?

A: Pra mim? É muito bom, é bom, que conversa melhó com os filhos, com as pessoas que convive no trabalho, vizinho, colega... 
colega (ininteligível) coisas, né? É muito bom alfabetização, tudo é maravilhoso! Né, se eu tô numa parada assim de ônibus querê pegá ônibus e num sabê, né? Nem lê, nem escrevê, é uma coisa muito importante. Eu acho que todo mundo hoje tem que tá direitinho, até que pessoas, as escolas tá cheia, eu tava vendo uma reportagem, na...na (TV) Globo, que a faxa de mulher de 55 a 56 ano, é tá 30 e tanto por cento nas escola, tá mais que os jovem, na faxa de 60 a 69, tá estudando mais que os jovem, na faxa de 15 ano, de 25 só tem $16 \%$ estudando, e tão fazendo faculdade, se vê que coisa assim, maravilhosa, graça a Deus que as mulheres num tão (ininteligível) num se sente mais, ah eu não sô ninguém, vô tê que ficá em casa, não, elas já tendo assim uma boa vista dos estudo, né? É muito bom.

Para A, existe a preocupação com os filhos ao lado da preocupação com o trabalho, o que significa a recontextualização do discurso da maternidade, um discurso da sociedade tradicional (Magalhães, 2005). Porém, o que ressalta na entrevista é a transformação identitária que é parte do atual discurso do trabalho. Citando reportagem da televisão, A demonstra a crença de sua geração de mulheres, que aposta no letramento e na profissionalização como formas de enfrentar o desemprego, como também de promoção no trabalho.

\section{ConsideraÇões Finais}

Mills (1995: 2) faz a seguinte observação a respeito das identidades de gênero:

As ideologias de gênero não são apenas opressoras e nem são simplesmente impostas às mulheres pelos homens. As mulheres e os homens constroem seu próprio sentido do 'eu' dentro dos limites de seus quadros discursivos, e constroem seus prazeres e desenvolvimento emocional, freqüentemente como resistência consciente a essas restrições, e, também, como forma de consentimento ${ }^{6}$.

Como Mills, entendemos que as transformações identitárias no campo do letramento precisam ser debatidas na perspectiva crítica do

\footnotetext{
${ }^{6}$ Tradução de I. Magalhães.
} 
poder, considerando o dinamismo das práticas sociais e a possibilidade de apropriação dessas transformações por discursos opressores como o discurso do trabalho. Mills defende, ainda, a posição de resistência, que, diante de obstáculos intransponíveis, recai na submissão. Nesse sentido, cabe destacar a relevância dos direitos discursivos, dentro de uma agenda de debates sobre as transformações identitárias no local de trabalho. Tais direitos, que são fundamentais para o exercício pleno da cidadania, estão no centro das discussões sobre a reformulação da esfera pública.

\section{REFERÊNCIAS BIBLIOGRÁFICAS}

Barton, D. Literacy. An introduction to the ecology of written language. Oxford, Grã-Bretanha, e Cambridge, E.U.A.: Blackwell, 1994. — e Hamilton, M. Local literacies. Londres e Nova York: Routledge, 1998. --- et al. (orgs.) Situated literacies. Londres e Nova York: Routledge, 2000. Bernstein, B. Pedagogy, symbolic control and identity. Theory, research, critique. Londres e Bristol: Taylor \& Francis, 1996.

---. Official knowledge and pedagogic identities. In: F. Christie (org.) Pedagogy and the shaping of consciousness. Londres e Nova York: Continuum, 1999, p. 246-261.

Bourdieu, P. Language ES symbolic power. Org. J. Thompson. Trad. G. Raymond e M. Adamson. Cambridge, Grã-Bretanha: Polity Press, 1991.

Butler, J. Gender trouble. Nova York e Londres: Routledge, 1990.

Cameron, D. Verbal hygiene. Londres e Nova York: Routledge, 1995.

Chouliaraki, L. e Fairclough, N. Discourse in late modernity. Rethinking critical discourse analysis. Edimburgo, Escócia: Edinburgh University Press, 1999.

Fairclough, N. Language and power. Londres e Nova York: Longman, 1989. ---. Dialogue in the public sphere. In: S. Sarangi e M. Coulthard (orgs.) Discourse and social life. Harlow, Essex, Grã-Bretanha: Pearson Education Limited, 2000a.

—. New labour, new language? Londres e Nova York: Routledge, $2000 \mathrm{~b}$.

---. The dialectics of discourse. Textus, XIV (2): 3-10, 2001a.

---. Discurso e mudança social. Coord. trad., revisão e prefácio à ed. bras. I. Magalhães. Brasília: Editora Universidade de Brasília, 2001 b. 
---. Analysing discourse. Textual analysis for social research. Londres e Nova York: Routledge, 2003.

Gee, J. Social linguistics and literacies. Londres, Nova York e Filadélfia: The Falmer Press, 1990.

Giddens, A. Modernity and self-identity. Self and society in the late modern age. Cambridge, Grã-Bretanha: Polity Press, 1991.

Habermas, J. Consciência moral e agir comunicativo. Trad. G. A. de Almeida. Rio de Janeiro, RJ: Tempo Brasileiro, 1989.

Harvey, D. Condição pós-moderna. Uma pesquisa sobre as origens da mudança cultural. Trad. A. U. Sobral e M. S. Gonçalves. 9 ed. São Paulo, SP, Brasil: Edições Loyola, 2000.

Heath, S. B. Ways with words. Language, life, and work in communities and classrooms. Cambridge, Grã-Bretanha: Cambridge University Press, 1983.

Magalhães, I. Práticas discursivas de letramento. A construção da identidade em relatos de mulheres. In: A. B. Kleiman (org.) Os significados do letramento. Campinas, SP, Mercado de Letras, 1995a.

---. Beliefs about literacy in a Brazilian community. International Journal for Educational Development, 15 (3): 263-276, 1995 b.

--- A critical discourse analysis of gender relations in Brazil. Journal of Pragmatics, 23: 183-197, 1995c.

---. Linguagem e identidade em contextos institucionais e comunitários. Cadernos de Linguagem e Sociedade, Brasília, 2 (1): 42-61, 1996.

---. Eu e tu. A constituição do sujeito no discurso médico. Brasília, Thesaurus, 2000.

--- Análisis crítico del discurso e ideología de género em la Constitución brasileña. In: L. Berardi (org.) Análisis crítico del discurso. Perspectivas latinoamericanas. Santiago, Chile: Frasis Editores, 2003, p. 17-50.

--- Teoria crítica do discurso e texto. Linguagem em (Dis)curso, 4, 2004a. Disponível em: <http://www.unisul.br/paginas/ensino/pos/linguagem/0403/05.htm $>$

---. Unequal discourse rights in adult literacy sites in Brazil. Comunicação apresentada no Sociolinguitics Symposium 15. University of Newcastle, Newcastle upon Tyne, Grã-Bretanha, 1-4 de abril de 2004b.

---. Interdiscursivity, gender identity and the politics of literacy in Brazil. 
In: M. Lazar (org.) Feminist Critical Discourse Analysis. Nova York: Palgrave, 2005, p.

Martin-Jones, M. e Jones, K. (orgs.) Multilingual literacies. Amsterdã/Filadélfia: John Benjamins, 2000.

Mills, S. 1995. Feminist stylistics. Londres e Nova York: Routledge, 2000.

Moita-Lopes, L. P. Identidades fragmentadas. Campinas, SP, Mercado de Letras, 2002.

Street, B. V. Literacy in theory and practice. Cambridge, Grã-Bretanha: Cambridge University Press, 1984.

—. Social literacies. Londres e Nova York: Longman, 1995.

---. Literacy events and literacy practices. In: M. Martin-Jones e K. Jones (orgs.), op. cit., 2000, p. 17-29.

Talbot, M. Language and gender. Cambridge, Grã-Bretanha: Polity Press, 1998.

Walsh, C. Gender and discourse. Language and power in politics, the church and organisations. Harlow, Grã-Bretanha: Pearson Education Limited, 2001. 